\title{
TAGASIPÖÖRDUMINE FILOLOOGIA JUURDE: VAADE AMEERIKAST
}

Terminil filoloogia on eri keeltes ja teaduskultuurides erinev tähendus ja maine. Mõnel pool, nagu näiteks Prantsusmaal, on see mõistena vähe kasutusel ega moodusta omaette teadusvaldkonda, samas kui teisal, näiteks Venemaal või Saksamaal, on tegemist sügavalt juurdunud akadeemilise traditsiooniga. Ingliskeelsetes maades on filoloogia olnud ajalooliselt kõrges hinnas, ent minetanud XX sajandil suure osa oma akadeemilistest positsioonidest. Seda huvitavam on diskussioon „tagasipöördumisest filoloogia juurde" (return to philology), mida on ingliskeelses teadusmaailmas peetud vahelduva eduga viimased kolmkümmend aastat ja mis päris viimasel ajal näib ajavat üha uusi siirdeid. Siinne lühike lugu, omalaadi metafiloloogiline motiivianalüüs, pakubki sissevaate sellesse peamiselt PõhjaAmeerikas peetud diskussiooni, sooviga tõmmata kodused arutelud filoloogia tulevikust veidi laiemale rahvusvahelisele kanvaale.

$$
* * *
$$

Filoloogia juurde tagasipöördumise motiivi tõi käibesse tuntud Belgia päritolu Ameerika kirjandusteadlane Paul de Man (1919-1983). Õigupoolest on see ootamatu, sest Ameerika dekonstruktivismi isaks peetud de Man seostub paljudele kõige muu kui filoloogiaga. Kuid de Mani kiitust filoloogiale, mille ta sõnastas 1982. aastal, võibki käsitada kavala retoorilise käiguna, mille abil vaigistada häält tõstvad kriitikud. 1971. aastal Yale’i ülikooli kirjandusprofessoriks valitud de Man muutis selle maineka ülikooli üheks moodsa kirjandusteooria tõmbekeskuseks, Nietzsche, Heideggeri ja Derrida ideedega tembitud mõjukaks teoreetiliseks platsdar- miks, mida tunneme Yale'i koolkonna nime all (vt viimati Miller 2015). De Mani ja tema mõttekaaslaste ideed levisid kiiresti, ent pälvisid ajapikku üha enam kriitikat. 1980. aastate alguseks oli vastasseis konservatiivsemate kolleegidega jõudnud haripunkti, mille üheks ilmekaks näiteks on Harvardi kirjandusprofessori Walter Jackson Bate'i (1918-1999) teravalt kriitiline artikkel Yale'i koolkonna aadressil, mis ilmus 1982. aastal Harvard Magazine'is (Bate 1982). Nimelt sellele Bate'i kriitikale võttiski de Man vastata oma artikliga "Tagasipöördumine filoloogia juurde", mis ilmus 1982. aasta detsembris Times Literary Supplementis (de Man 1982). Artikkel avaldati osana laiemast arutelust kirjanduse õpetamise väljavaadete üle, kuid de Man kasutas pakutud foorumit esmajoones oma teoreetiliste positsioonide kaitsmiseks kasvava kriitika eest. Nagu öeldud, valis ta oma kaitsekilbiks filoloogia üleva mõiste, mida ta käsitab kaunis avaralt kui tekstide lähilugemise meetodit, mis ei hooli kontekstist ja keskendub tekstide seesmisele ülesehitusele, nende keelelise struktuuri lahkamisele. Filoloogia osutub niisiis dekonstruktivismi liitlaseks: „pöördumine teooriasse oli tagasipöördumine filoloogiasse”, nagu de Man oma seisukoha resümeerib (1986: 24). Ta leiab, et nimelt tagasipöördumine filoloogia juurde, klassikaliste retooriliste analüüsitehnikate juurde, on see, mis tema vastaseid ärritab, mis kõigutab nende enesestmõistetavaks peetud veendumusi (de Man 1986: 25).

See aasta enne autori surma kirjutatud lühike essee sai laiema kõlapinna neli aastat hiljem, kui ta ilmus uuesti de Mani postuumses autorikogumikus "Vastupanu teooriale” (de Man 1986: 21-36). Seda kordustrükki võibki pidada 
uue „metafiloloogilise” motiivi tõeliseks sünniks, mille ümmargust tähtpäeva saame seega tänavu tähistada.

Kõige esimesena haakis ennast eksplitsiitselt uue motiivi külge pärast de Mani Yale’i ülikoolis töötanud keskaja kirjanduse professor Lee Patterson (1940-2012). 1994. aastal avaldas ta artikli „Tagasipöördumine filoloogia juurde", mis ilmus Ameerika medievistika väljavaateid vaagivas kollektiivses koguteoses (Patterson 1994). Kuigi Patterson sätib ennast de Mani sõiduvette, on tema artikkel tegelikult hea näide sellest, kuidas vastne motiiv hakkas kiiresti oma elu elama. Nimelt on Pattersoni sõnavõtt osa ühest teisest vaidlusest, mida peeti medievistide seltskonnas „uusfiloloogia” (new philology) programmi üle 1980. aastate lõpus ja 1990. aastate alguses. Uusfiloloogia sihid sõnastas John Hopkinsi ülikooli medievist Stephen Nichols esimest korda 1988. aastal ajakirjas Romanic Review (Nichols 1988) ja ulatuslikumalt ajakirja Speculum erinumbris 1990. aastal (Nichols 1990). Uusfiloloogia manifesteeris ennekõike uut suhtumist keskaegsetesse tekstidesse, soovi uurida vanu käsikirju kui terviklikke kultuurinähtusi, pöörata tähelepanu nende materiaalsele iseloomule, sotsiaalsele toimele, pisimatelegi detailidele, samas loobudes „algteksti” rekonstrueerimise ideaalist, käsitades tekste avatuna, pigem protsessina, mouvance'ina (Paul Zumthori(1987) termin), mitte lõpetatud tulemusena. Uusfiloloogia põhjustas erialaringkondades teravaid debatte (vt nt Busby 1993; Pickens 1994) ja Pattersoni soov oligi anda artikliga oma panus uusfiloloogia kaitseks, sidudes selle de Mani autoriteetse eeskujuga.

Järgmise autorina annab de Mani lansseeritud motiivile 2002. aastal hoogu uue põlvkonna mõjukamaid Ameerika kirjandusteoreetikuid, Cornelli ülikooli kirjandusprofessor Jonathan Culler. Culler oli sõnastanud oma vaated filoloogia rollist juba kümmekond aastat varem, kui ta osales 1989 . aastal Harvardi ülikoolis peetud konverentsil „Mis on filoloogia?”. Seal pidas ta ettekande pealkirjaga „Antifundatsionistlik filoloogia”, mis aasta hiljem ilmus ajakirja Comparative Literature Studies erinumbris (Culler 1990). Culleri käsituses ei saa filoloogiat pidada kirjandusteaduse vundamendiks, alusdistsipliiniks, millel rajaneb kõik muu, sest tegelikult lähtub filoloogiline uurimistöö omakorda paljudest mõistetest ja eeldustest, mis on laenatud teistest valdkondadest, sh kirjandusteadusest. Filoloogiat peaks käsitama pigem kriitilise distsipliinina, mis annab meile vahendid igasuguse analüüsi, sh filoloogilise analüüsi kriitiliseks hindamiseks.

Kui 2001. aastal tähistati Yale’i ülikooli 300. aastapäeva, peeti märtsi lõpus maha esinduslik vestlusring humanitaaria väljavaadetest. Üks arutelus osalejatest oli Culler, kes pealkirjastas oma sõnavõtu kui „Tagasipöördumine filoloogia juurde", mis aasta hiljem ilmus ajakirjas Journal of Aesthetic Education (Culler 2002). Culleri sõnavõtt on põhiosas de Mani paarkümmend aastat tagasi ilmunud artikli kommentaar, soov avada ühelt poolt toonaseid kontekste, teiselt poolt aga rõhutada de Mani sõnumi jätkuvat aktuaalsust. Ta toonitab, kui ootamatult de Mani üleskutse omas ajas kõlas, sest „filoloogid olid lõpuks ju vaenlased, need, kes pilkasid mitte üksnes teooriat, vaid isegi tõlgendamist" (Culler 2002: 14). Ta tunnustab de Mani kavalat käiku vastastel vaip jalge alt tõmmata, sidudes kokku teooria ja filoloogia, näidates, et Yale’i dekonstruktivistid järgivad filoloogia klassikalisi ideaale truumalt kui nende Harvardi vanamoelised kolleegid.

Veel enne Culleri artiklit jõudis uue hinnalise panuse motiivi arengusse anda tuntud Palestiina päritolu Ameerika kirjandusteadlane ja kultuurikriitik Edward Said (1936-2003), kes 2000. 
aasta alguses pidas Columbia ülikoolis kolmeosalise loengusarja, mis täiendatud kujul ilmus postuumselt 2004. aastal omaette raamatuna „Humanism ja demokraatlik kriitika” (Said 2004). Loengusarja viimane ülesastumine, raamatus kolmas peatükk kannab pealkirja "Tagasipöördumine filoloogia juurde" ja võtab kokku Saidi pikaaegse huvi filoloogilise uurimistöö vastu. Väärib kohe märkimist, et Said ei maini oma essees kordagi Paul de Mani nime, kuigi pole põhjust kahelda, et ta oli motiivi varasema ajalooga hästi kursis, nagu saab ridade vahelt hõlpsalt välja lugeda. Kummati erineb Saidi filoloogiakäsitus sootuks de Mani omast. Kuigi ta jagab viimase arusaama filoloogiast kui tekstide aktiivsest lähilugemisest, on Saidile väga oluline dialoog autoriga, autorikavatsuse tuvastamine, ajaloolise konteksti arvestamine. Saidi lähenemises on filoloogia humanistlik distsipliin, mis pakub kriitilist perspektiivi käibetõdedele ja valitsevatele ideoloogiatele, mis väärtustab indiviidi ja loob võimalusi uueks identiteediloomeks. Teatud mõttes sulavad filoloogia ja humanism Saidi tõlgenduses üheks, humanism ei ole muud kui tekstide lugemine, vaatenurkade vahetamine, kogemuste jagamine vabaduste loomine filoloogiliste vahenditega.

Saidi surmaeelne kiitus filoloogiale oli ühest küljest üllatav, sest suur osa tema varasest loomingust, eesotsas „Orientalismiga" (Said 1978), tegeleb filoloogia ideoloogiliste aluste paljastamise ja kritiseerimisega. Teisest küljest sidus Said ennast filoloogia traditsiooniga väga varakult, ta on alati toonitanud, et kujundas oma erialased arusaamad Giambattista Vico, Friedrich Nietzsche, Ernst Robert Curtiuse, Erich Auerbachi, Leo Spitzeri ja teiste suurte filoloogide töid lugedes (vt nt McCarthy 2010: 20-26). Iseäranis tähenduslik oli Saidile Auerbachi kui XX sajandi suurima pagulasfiloloogi looming, mida kinnitab muuhulgas 1969. aastal Maire Jaanusega kahasse inglise keelde tõlgitud Auerbachi artikkel „Maailmakirjanduse filoloogia" (Auerbach 1969) ja 2003. aastal kirjutatud pikk sissejuhatus „Mimesise” juubeliväljaandele, mille Said mugandas ühtlasi peatükiks raamatusse „Humanism ja demokraatlik kriitika” (Said 2003, 2004: 85-118).

Saidi onnistus kanoniseeris motiivi lõplikult ja praegu võime tõdeda, et „tagasipöördumine filoloogia juurde" on muutunud sagedaseks külaliseks väga erinevates aruteludes ja motiiv on ühtlasi leidnud endale esimesed uurijad. Kõige olulisem selles vallas on olnud tõenäoliselt nimeka Ameerika kirjandusteadlase, pikaajalise National Humanities Centeri juhataja Geoffrey Galt Harphami uurimistöö. Paaris põhjalikus artiklis, mis juba pealkirjas haagivad ennast filoloogia juurde tagasipöördumise külge, on ta kriitiliselt vaaginud motiivi kujunemislugu ja näidanud, kuivõrd erinevalt on eri autorite töödes filoloogiat mõistetud, ent ühtlasi on ta välja pakkunud oma alternatiivse arusaama filoloogia rollist ja võimalustest tänapäeval (Harpham 2005, 2009). Kuid näiteid motiivi edasiarendustest leiame hilisemastki ajast: nii on Duke'i ülikooli Itaalia uuringute professor Martin G. Eisner oma artiklis „Tagasipöördumine filoloogia juurde ja kirjanduskriitika tulevik" (Eisner 2011) pakkunud välja idee uuest, avarast filoloogiast, mis hõlmaks tekstide analüüsi nende kirjutamisest kuni vastuvõtuni (sh tõlkimise ja mugandusteni). Oregoni ülikooli itaalia kirjanduse professor Massimo Lollini jällegi tegi samal aastal katse siduda filoloogia juurde tagasipöördumise motiiv digitaalse pöördega filoloogias, hüpertekstide analüüsiga (Lollini 2011). Uue vindi keeras motiivile peale Duke'i ülikooli kirjandusõppejõud Aarthi Vadde, kui ta pani ühele oma hiljutisele raamatuarvustusele pealkirjaks „Uus tagasipöördumine filoloogia juurde" 
(Vadde 2012). Teatud mõttes sai selle tekstiga motiivile ring peale tehtud, kolme kümnendi jooksul on sellest välja pigistatud ilmselt kõik mis võimalik.

$$
* * *
$$

Kuid huvitav on täheldada, et kas kõnealuse motiivi tõttu või sellest sõltumatult saame viimastel aastatel tunnistada filoloogia väga jõulist tagasipöördumist Ameerika akadeemilistesse aruteludesse. Vaid õige väikese liialdusega võib väita, et filoloogia pole olnud Ameerikas ligemale sada aastat nii suure tähelepanu all kui viimasel viiel aastal. Missouri ülikooli klassikalise filoloogia õppejõud Sean Gurd, üks aktiivsemaid filoloogia eestkõnelejaid, kirjutas 2010. aastal koguteose „Filoloogia ja selle ajalood” tutvustuseks: „Praegu, pärast rohkem kui kakskümmend aastat pidevaid „tagasipöördumisi filoloogia juurde”, mida kuulutati dekonstruktsiooni, uue medievistika, kriitilise bibliograafia ja globaalselt teadliku aktivistliku kriitika lipu all, on filoloogia muutunud uuesti auväärseks hoiakuks tänapäeva kirjandusteadlaste jaoks" (Gurd 2010 tagakaanel). Gurdi kogumik oli üks esimesi pääsukesi, mis kuulutas filoloogiale uut tulevikku Ameerika akadeemias. Seni kõige olulisema panuse on pakkunud Notre-Dame'i ülikooli emeriitprofessor James Turner oma mastaapse monograafiaga „Filoloogia: tänapäeva humanitaaria unustatud lätted", mis ilmus 2014. aastal (Turner 2014). See on väga ambitsioonikas katse panna viiesajal leheküljel kirja lääne humanitaarteaduste ajalugu filoloogia vaatenurgast. ${ }^{1}$

${ }^{1}$ On huvitav märkida, et rööpselt Turneriga võttis humanitaarteaduste ajaloo kaardistamise ette Hollandi õpetlane Rens Bod (2013), kelle vaatevinkel on olulisemalt laiem, haarates filoloogia kõrval vaatlusse mitmed teisedki humanitaaria harud (muusikateadus, loogika, kunstiajalugu, keeleteadus, ajalookirjutus, retoorika ja poeetika). Bodi algatusel on viimasel kümnel
Turner alustab tõdemusega, et XXI sajandi alguseks oli filoloogia ingliskeelses maailmas unustusse langenud, suure osa läinud sajandist on filoloogiat rünnatud, pilatud ja ära kasutatud, samal ajal kui XIX sajandil oli tegemist ühe kõige auväärsema distsipliiniga. Turner läheb oma käsitluses kaugemalegi, väites, et tänapäeva humanitaaria ongi sündinud filoloogia rüpest. Selleks teeb ta ulatusliku ekskursi filoloogia lätetele, alustades vaatlusega Vana-Kreekast, ent süvendades oma käsitlust alates XVIII sajandi keskpaigast ja keskendudes peamiselt Briti ja Ameerika filoloogilistele traditsioonidele. Kuigi Turneri raamatule on lihtne paljutki ette heita, alates humanitaaria liialt lihtsustavast taandamisest filoloogiale kuni ingliskeelse maailma põhjendamatule eelistamisele, on see suurepärane näide filoloogia taassünni uutest lootustest.

Sedasama tulevikulootust kannab noorte Ameerika ja Saksa germanistide kogumik „Filoloogia tulevik”, mis ilmus samuti 2014. aastal (Bajohr jt 2014). Kogumiku sissejuhatus annab hea ülevaate filoloogia üle peetud uuematest arutlustest Ameerikas ning on kantud veendumusest, et termin filoloogia kannab endas väge, mis ei kao kunagi, mille tõmbejõud võib küll kohati kahaneda, et siis aga uuesti kasvada. Veendumus filoloogia uues tõmbejõus kannab kogumiku kümmet kaastööd, mille haare ulatub Nietzsche ja Hamanni tõlgendustest digitaalfilo-

aastal peetud viis esinduslikku konverentsi humanitaarteaduste ajaloost „Making of the Humanities", mis on andnud humanitaarteaduste ajaloo uurimisele sisse uue hoo, vt http://www.historyofhumanities.org/ (13. VI 2016). Konverentsiettekannete põhjal on ilmunud mitu mahukat koguteost, mille esimesed kolm köidet on tasuta veebis allalaetavad, vt http://www.oapen.org/ search?keyword $=\% 22$ The + Making + of + the + Humanities\%22 (13. VI 2016). Hea kriitilise ülevaate nii Turneri kui ka Bodi uurimistööst pakub Stefan Collini (2015). 
loogia katsetusteni. Otsapidi saab kogumikuga siduda ka ühe teise noorte filoloogide algatuse, nimelt Berliini Vaba Ülikooli juurde rajatud rahvusvahelise uurimiskeskuse Zukunftsphilologie ('tulevikufiloloogia'). ${ }^{2}$ Keskuse siht on toetada tänapäevaseid filoloogiauuringuid globaalses võtmes, siduda erinevate kultuuride tekstipärandeid ja nende uurimist. 2016. aastal asutati Brilli kirjastuse juurde uus ajakiri Philological Encounters, mille avanumbri kirev sisukord annab hästi aimu keskuse suurtest ambitsioonidest.

Tõenäoliselt kõige mõjukamaks ja laiahaardelisemaks filoloogia eest võitlejaks Ameerika akadeemias, ühtlasi Berliini Zukunftsphilologie keskuse peamiseks ideoloogiks on kujunenud Harvardi ülikooli sanskriti keele ja kirjanduse professor Sheldon Pollock. Märgiliseks võib lugeda tema 2009. aastal ilmunud artiklit „Tulevikufiloloogia? Ühe pehme teaduse saatus kõvas maailmas", mille algus kõneleb iseenda eest: „Tänapäeva filoloogia põhiküsimus, nagu mina seda näen, on see, kas filoloogia jääb üldse ellu; ja filoloogia ellujäämine ning see, kuidas seda tagada, on ainus, mis mind huvitab" (Pollock 2009: 931, vrd Pollock 2015: 34). Filoloogiat käsitab Pollock tekstide mõtestamise teadusena (the discipline of making sense of texts), piiramata seda sugugi pelgalt lääne traditsiooniga, vaid kutsudes üles globaalsele filoloogiale. Sellest üleskutsest sündis Pollocki hiljutine algatus, üks viimase aja kaalukamaid panuseid filoloogia uuendamisse: koos kahe kolleegiga toimetatud koguteos „Maailmafiloloogia”,misneljateistkümnespeatükis demonstreerib globaalse filoloogia võimalusi (Pollock jt 2015). Kogumikus eritletakse araabia, heebrea, hiina, jaapani, ladina, pärsia, saksa, sanskriti, türgi, vanakreeka jt keeltes

2 Vt http://www.forum-transregionalestudien.de/revisiting-the-canons-of-textualscholarship.html (13. VI 2016). kirjutatud tekste, pakkudes korraga nii sissevaateid filoloogilise mõtlemise ajalukku erinevates kultuurides kui ka analüüsinäiteid tänapäeva filoloogia võimalustest. Pollocki algatusele on hiljuti sekundeerinud Briti The Open University kirjandusprofessor Suman Gupta raamatuga globaalsest inglise filoloogiast, mis kaardistab viimaste kümnendite inglise filoloogia arenguid mitmes riigis, fookusega üleilmsetel väljakutsetel, millega distsipliin tänapäeval silmitsi seisab (Gupta 2015).

Pollocki pakutud „maailmafiloloogia” on siiski vaid üks näide, kuidas uuel aastatuhandel on ingliskeelses maailmas püütud filoloogiat viljastada uute eesliidetega, mis aitaksid vana mõistet muuta konkurentsikõlblikumaks (vt Eisner 2011; Warren 2010). Eespool juba mainisin medievistide katset üles soojendada XIX sajandil vermitud „uusfiloloogia” nimetust, nagu ka Culleri kuulutatud "antifundatsionistlikku filoloogiat”, mis oleks kohane postmodernsele ajastule. Culleriga sarnases vaimus on Dartmouthi ülikooli kirjandusprofessor Michelle R. Warren käinud välja „postfiloloogia” idee, mis lõimiks postkolonialismi ja poststrukturalismi õppetunnid filoloogilisse traditsiooni (Warren 2003). Toronto ülikooli medievist William Robins on toonitanud filoloogia mitmekesist, kohati paradoksaalset iseloomu, mis on ajendanud teda sõnastama „disjunktiivse filoloogia” käsitust, mis püüaks rinnastada filoloogia erinevaid harusid (Robins 2004). Eespool mainitud Sean Gurd on kutsunud üles „radikaalsele filoloogiale”, mille taotluseks on tähelepanu pööramine (vanade) tekstide ainulisusele, nende sattumusliku, ainelise ja ajaloolise iseloomu väärtustamisele (Gurd 2005). Viimaks ei ole filoloogia mõistagi pääsenud digitaalsest pöördest, mille käigus on kuju võtnud digifiloloogia järjest mõjukam suundumus (vt McGann 2013; ühe praktilise näitena võib nimetada alates 2012. aastast ilmuvat ajakirja Digital 
Philology: A Journal of Medieval Cultures).

$* * *$

Kui visandatud ülevaate pealt tihata üldistada, siis näikse, et vähemalt Ameerika akadeemilises kontekstis on põhjust filoloogia lagunemise asemel rääkida filoloogia tagasitulekust. Filoloogia on ingliskeelses maailmas üha ulatuslikumate ja intensiivsemate ristviljastamiste objekt, sellega seotakse järjest sagedamini humanitaaria helgeid väljavaateid uuel aastasajal. Teisalt saab tõdeda, et mõistena on filoloogia pea viimseni ära trööbatud, see

\section{Kirjandus}

Auerbach, Erich 1969. Philology and Weltliteratur. Tlk Maire ja Edward Said. - Centennial Review, kd 13, nr 1, lk 1-17.

Bajohr, Hannes, Dorvel, Benjamin, Hessling, Vincent, Weitz, Tabea (toim) 2014. The future of philology. - Proceedings of the $11^{\text {th }}$ Columbia University German Graduate Student Conference. Newcastle upon Tyne: Cambridge Scholars Publishing.

B a te, Walter Jackson 1982. The crisis in English studies. - Harvard Magazine, kd 85, nr 12, lk 46-53.

B od, Rens 2013. A New History of the Humanities: The Search for Principles and Patterns from Antiquity to the Present. New York: Oxford University Press.

Busby, Keith (toim) 1993. Towards a Synthesis? Essays on the New Philology. Amsterdam: Rodopi.

Collini, Stefan 2015. Seeing a specialist: The humanities as academic disciplines. - Past and Present, nr 229, lk 271-281.

Culler, Jonathan 1990. Antifounda- on muutunud iselaadi tühjaks tähistajaks, humanitaarteaduste kuldajastu sünonüümiks, mida igaüks täidab oma soovide, ootuste ja ihadega. Sellest saab soovi korral järeldada, et filoloogia nimes on midagi igavesti peibutavat, umbes nagu filosoofiagi mõistes, selle sümboolne kapital on tagasilöökide kiuste aina priskem, mis tähendab, et üha uued põlvkonnad saavad sellelt dividende lõigata. Nii tundubki, et me jääme ikka ja jälle filoloogia juurde tagasi pöörduma, filoloogia ei lagune kunagi, see jääb igavesti naasma, olgu siis tõrjutu, kummituse või kangelasena.

MAREK TAMM tional philology. - Comparative Literature Studies. What is Philology?, kd 27, nr 1, lk 49-52.

$\mathrm{Culler}$, Jonathan 2002. The return to philology. - Journal of Aesthetic Education, kd 36, nr 3, lk 12-16.

de Man, Paul 1982. The return to philology. - Times Literary Supplement, 20. XII, lk 1355-1356.

de Man, Paul 1986. The Resistance to Theory. Minneapolis-London: University of Minnesota Press.

Eisner, Martin G. 2011. The return to philology and the future of literary criticism: Reading the temporality of literature in Auerbach, Benjamin, and Dante. - California Italian Studies, kd 2, nr 1. http://escholarship. org/uc/item/4gq644zp (12. VI 2016).

Gupta, Suman 2015. Philology and Global English Studies: Retracings. New York: Palgrave Macmillan.

Gurd, Sean Alexander 2005. For a radical philology. - Iphigenias at Aulis: Textual Multiplicity, Radical Philology. Ithaca: Cornell University Press, lk 36-55. 
Gur d, Sean (toim) 2010. Philology and its Histories. Columbus: Ohio State University Press.

H a r p h a m, Geoffrey Galt 2005. Returning to philology: The past and future of literary study. - New Prospects in Literary Research. Toim Koen Hilberdink. Amsterdam: Royal Netherlands Academy of Arts and Sciences, lk 9-26.

H a r ph a m, Geoffrey Galt 2009. Roots, races, and the return to philology. Representations, nr 106, lk 34-62.

Lollini, Massimo 2011. Return to philology and hypertext in and around Petrarch's Rvf. - Humanist Studies \& the Digital Age, kd 1, nr 1, lk 66-79.

McCarthy, Conor 2010. The Cambridge Introduction to Edward Said. Cambridge: Cambridge University Press.

M c G a n n, Jerome 2013. Philology in a new key. - Critical Inquiry, kd 39, nr 2, lk 327-346.

Miller, Hillis Joseph 2015. Tales out of the (Yale) School. - Theoretical Schools and Circles in the Twentieth-Century Humanities. Literary Theory, History, Philosophy. Toim Marina Grišakova, Silvi Salupere. New York: Routledge, lk 115-132.

Nichols, Stephen G. 1988. Editor's preface. - Romanic Review. The Legitimacy of the Middle Ages, kd 79, nr 1, lk 1-16.

Nichols, Stephen G. 1990. Introduction: Philology in a manuscript culture. - Speculum. A Journal of Medieval Studies. The New Philology, kd 65, nr 1, lk 1-10.

Patterson, Lee 1994. The return to philology. - The Past and Future of Medieval Studies. Toim John Van Engen. Notre-Dame: University of Notre-Dame Press, lk 231-244.

Pickens, Rupert T. 1994. The future of old French studies in America. The „old" philology and the crisis of the "new". - The Future of the Middle Ages: Medieval Literature in the 1990s. Toim William D. Paden. Gainesville, FL: University Press of Florida, lk 53-86.
Pollock, Sheldon 2009. Future philology? The fate of a soft science in a hard world. - Critical Inquiry, kd 35, nr 4, lk 931-961.

Pollock, Sheldon 2015. Philologia rediviva? - Bulletin of the American Academy of Arts \& Sciences, kd 68, nr 4, lk 34-36.

Pollock, Sheldon, Elman, Benjamin A., Chang, Ku-ming Kevin (toim) 2015. World Philology. Cambridge, Mass.; London: Harvard University Press.

Robins, William 2004. Toward a disjunctive philology. - The Book Unbound: Editing and Reading Medieval Manuscripts and Texts. Toim Siân Echard, Stephen Partridge. Toronto: University of Toronto Press, lk 144-158.

Said, Edward W. 1978. Orientalism. New York: Pantheon Books.

Said, Edward W. 2003. Introduction to the fiftieth-anniversary edition. Erich Auerbach, Mimesis. The Representation of Reality in Western Literature. Tlk Willard R. Task. Princeton -Oxford: Princeton University Press, lk ix-xxxii.

S a id, Edward W. 2004. Humanism and Democratic Criticism. New York: Columbia University Press.

Zumthor, Paul 1987. La lettre et la voix. De la „littérature” médiévale. Paris: Seuil.

Turner, James 2014. Philology: The Forgotten Origins of the Modern Humanities. Princeton, NJ: Princeton University Press.

Vadde, Aarthi 2012. The re-return to philology. - Novel, kd 45, nr 3, lk 461-465.

W arren, Michelle R. 2003. Post-philology. - Postcolonial Moves: Medieval Through Modern. Toim Patricia Clare Ingham, Michelle R. Warren. New York: Palgrave Macmillan, lk 19-45.

W a rren, Michelle R. 2010. Introduction: Relating philology, practicing humanism. - PMLA, kd 125, nr 2, lk 283-288. 